\title{
Nicotinamide riboside has minimal impact on energy metabolism in mouse models of mild obesity
}

\author{
David M Cartwright1, Lucy A Oakey1', Rachel S Fletcher1, Craig L Doig1,2, Silke Heising1, Dean P Larner1, \\ Daniela Nasteska1, Caitlin E Berry1', Sam R Heaselgrave1, Christian Ludwig1, David J Hodson'1, Gareth G Lavery1,* and \\ Antje Garten (1) 1,3,*
}

1Institute of Metabolism and Systems Research, College of Medical and Dental Sciences, University of Birmingham, Birmingham, UK
${ }^{2}$ School of Science and Technology, Nottingham Trent University, Nottingham, UK

3Pediatric Research Center, Hospital for Child and Adolescent Medicine, Leipzig University, Leipzig, Germany

Correspondence should be addressed to A Garten: a.garten@bham.ac.uk

*(G G Lavery and A Garten contributed equally as joint last authors)

\begin{abstract}
Supplementation with precursors of NAD has been shown to prevent and reverse insulin resistance, mitochondrial dysfunction, and liver damage in mouse models of diet-induced obesity. We asked whether the beneficial effects of supplementation with the NAD precursor nicotinamide riboside (NR) are dependent on mouse strain. We compared the effects of NR supplementation on whole-body energy metabolism and mitochondrial function in mildly obese C57BL/6N and C57BL/6J mice, two commonly used strains to investigate metabolism. Male C57BL/6N and C57BL/6J mice were fed a high-fat diet (HFD) or standard chow with or without NR supplementation for 8 weeks. Body and organ weights, glucose tolerance, and metabolic parameters as well as mitochondrial $\mathrm{O}_{2}$ flux in liver and muscle fibers were assessed. We found that NR supplementation had no influence on body or organ weight, glucose metabolism or hepatic lipid accumulation, energy expenditure, or metabolic flexibility but increased mitochondrial respiration in soleus muscle in both mouse strains. Strain-dependent differences were detected for body and fat depot weight, fasting blood glucose, hepatic lipid accumulation, and energy expenditure. We conclude that, in mild obesity, NR supplementation does not alter metabolic phenotype in two commonly used laboratory mouse strains.
\end{abstract}

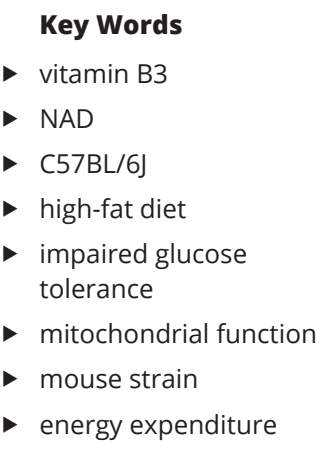

Journal of Endocrinology (2021) 251, 111-123

\section{Introduction}

Repletion of NAD with vitamin B3 precursors or metabolites, mainly nicotinamide riboside (NR) and nicotinamide mononucleotide (NMN) has been used widely in experimental animal studies to counteract negative consequences of metabolic and mitochondrial disorders. Beneficial effects on energy metabolism and mitochondrial function were found in animal models of diet-induced obesity (Yoshino et al. 2011, Cantó et al. 2012, Yoon et al. 2015, Mills et al. 2016, de Castro et al. 2020), liver damage (Gariani et al. 2016, Zhou et al. 2016, Mukherjee et al. 2017, Wang et al. 2018, Han et al. 2019), diabetes (Kakimoto \& Kowaltowkski 2016, Stromsdorfer et al. 2016, Trammell et al. 2016), and mitochondrial disease (Khan et al. 2014, Schöndorf et al. 2018). (c) 2021 The authors Published by Bioscientifica Ltd. Printed in Great Britain

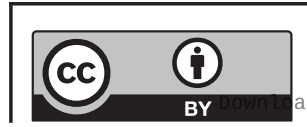

This work is licensed under a Creative Commons Attribution 4.0 International License. 
Several of these studies (Cantó et al. 2012, Gariani et al. 2016, Trammell et al. 2016, Zhang et al. 2016, Zhou et al. 2016, Wang et al. 2018, Han et al. 2019) were conducted with male $\mathrm{C} 57 \mathrm{BL} / 6 \mathrm{~J}$ or $\mathrm{C} 57 \mathrm{BL} / 6 \mathrm{JRj}$ mice $(\mathrm{B} 6 \mathrm{~J})$, a commonly used mouse model to study the effects of dietinduced obesity and glucose intolerance. A limitation of using these mice for metabolic studies is a deficiency in nicotinamide nucleotide transhydrogenase (Nnt), a mitochondrial enzyme crucial for maintaining redox balance (Toye et al. 2005, Ronchi et al. 2013). Mitochondria of B6J mice have a lower peroxide removal capacity as well as increased sensitivity to Ca2+-mediated permeability transition (Ronchi et al. 2013, 2016, Lopert \& Patel 2014, Navarro et al. 2017). Studies assessing the effects of nonfunctional Nnt in mice found derangements in glucose homeostasis and aggravated fatty liver disease (Toye et al. 2005, Williams et al. 2014, Fisher-Wellman et al. 2015, 2016, Rendina-Ruedy et al. 2015, Navarro et al. 2017) in B6J mice, although others did not see a difference in glucose metabolism (Wong et al. 2010).

Few human clinical trials have addressed supplementation of NAD with NR in elderly and mildly obese, but otherwise healthy, subjects. These studies reported no effects of NR supplementation on mitochondrial and endocrine pancreatic function as well as whole-body energy metabolism, although changes in muscle gene expression and circulating anti-inflammatory cytokines were detected (Dollerup et al. 2018, Martens et al. 2018, Dollerup et al. 2019a,b, Elhassan et al. 2019). The observed changes were accompanied by increased muscle nicotinic acid adenine dinucleotide, N-methyl nicotinamide, and N1-methyl-2 pyridone-5-carboxamide, while $\mathrm{NAD}^{+}$was elevated in the blood, but not in muscle (Elhassan et al. 2019).

We asked whether the choice of mouse strain could affect outcomes of NAD augmentation studies. We compared the effects of NR supplementation in male C57BL/6J mice to C57BL/6N mice which are competent for Nnt (Fisher-Wellman et al. 2016). A mild obesity phenotype was induced by a diet high in saturated fat (60\%) for 8 weeks (HFD), and whole-body energy metabolism and mitochondrial function were assessed. We found slight effects of NR on mitochondrial respiration in soleus muscle in both mouse strains that were not translated into decreases in body weight, improved glucose tolerance, or alterations in energy metabolism in either mouse strain. We conclude that a mild obesity phenotype is not influenced by NR supplementation in both $\mathrm{B} 6 \mathrm{~N}$ and B6J mice.

\section{Materials and methods}

\section{Animals}

Mice were purchased from Charles River, UK (B6J) and MRC Harwell, UK (B6N Taconic). Mice were group-housed in a standard temperature $\left(22^{\circ} \mathrm{C}\right)$ and humidity-controlled environment with $12 \mathrm{~h}$ light:12 h darkness cycle, except for indirect calorimetry experiments, where animals were single-housed for $72 \mathrm{~h}$. Nesting material was provided and mice had ad libitum access to food and water unless otherwise noted. Starting from an age of 7 weeks ( 9 weeks in case of B6N chow-fed mice), mice were fed either a standard chow (EUrodent diet 14\%, 5LF2*, 0.0074\% niacin) or a highfat diet (HFD, Brogaarden D12492i, 60\% calories from fat, $0.3 \%$ nicotinic acid) for 8 weeks. For NR supplementation, $3.0 \mathrm{mg} / \mathrm{mL}$ NR chloride (Chromadex Inc.) was dissolved in drinking water in light-protected bottles and changed every 3 days since this regimen was shown to lead to a stable increase in hepatic NAD (Mukherjee et al. 2017). NR stability was checked by incubation of NR in mouse drinking water at room temperature for 6 days followed by NMR quantification. After 6 days, the portion of NR was 95\% (Supplementary Fig. 1A, see section on supplementary materials given at the end of this article). The effect of NR supplementation on total NAD levels in the liver and cardiac muscle of HFD-fed B6J mice was checked by an enzymatic cycling assay (NAD/NADH Quantitation Colorimetric Kit, BioVision, Inc.). We detected higher NAD levels both in the liver (Supplementary Fig. 1B) and cardiac muscle (Supplementary Fig. 1C) of NR-supplemented compared to non-supplemented mice.

Mice were weighed weekly. Mice were sacrificed using cervical dislocation after exsanguination under isofluorane anesthesia. Liver, inguinal, and epididymal fat as well as skeletal muscle (tibialis anterior (TA), soleus) were immediately frozen in liquid $\mathrm{N}_{2}$ or used for mitochondrial respiration measurements. Genotyping was performed according to Nicholson et al. (2010) for each mouse to verify grouping into B6N or B6J strain (Supplementary Fig. 1D). A subgroup of tissues was weighed. All animal experiments were conducted in accordance with UK Home Office regulations, UK Animals (Scientific Procedures) Act 1986 under project license number 70/8516.

\section{Glucose homeostasis assessment}

Experiments were performed following a $5 \mathrm{~h}$ fast starting at $\sim 08: 00 \mathrm{~h}$. Blood glucose was monitored using the Contour XT glucometer (Bayer) from samples collected

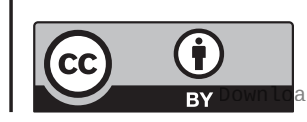

This work is licensed under a Creative Commons Attribution 4.0 International License. 
at the distal tail vein. Following an initial blood glucose measurement, glucose ( $2 \mathrm{~g} / \mathrm{kg}$ body weight) was injected intraperitoneally. Blood glucose was measured after 15, 30, 60,90 , and $120 \mathrm{~min}$.

\section{Hepatic lipid accumulation}

Quantification of liver triglycerides was performed using a triglyceride quantification kit (ab65336, Abcam) according to the manufacturer's instructions. One lobe (lobus hepatis sinister) was fixed in 4\% paraformaldehyde and paraffinembedded. Sections were stained with hematoxylin and images were taken at $20 \times$ magnification.

\section{Indirect calorimetry}

Energy expenditure, respiratory exchange ratio (RER), food and water intake of HFD-fed ( $n=10$ for each group) and chow-fed ( $n=4$ four for each group) were measured in a Phenomaster System (TSE systems, Bad Homburg, Germany). Briefly, animals were group-acclimatized for $24 \mathrm{~h}$ before isolation. On day 2 at 12:00 h, mice were removed from the home cages, weighed and their overall condition was checked, then placed into new cages in isolation. On the morning of day 3 , mice were visually checked for signs of stress at 09:00 $\mathrm{h}$ and food/drink consumption was recorded. If mice were not eating and/or drinking (determined as less than $1 \mathrm{~g}$ of food or $1 \mathrm{~mL}$ of water), they were removed from the experiment ( $n=1$ B6N mouse). For the data collection phase, mice were then left undisturbed until 13:00 h on day 5, where they were removed. Food/drink consumption data were checked again and mice were weighed. If the mice had not eaten or drank and/or had lost more than $20 \%$ body weight since day 1 , the data were excluded from the experiment ( $n=2 \mathrm{~B} 6 \mathrm{~N}$ mice). The last $48 \mathrm{~h}$ were used for data analysis. $\triangle R E R$ was calculated by subtracting the mean of the five highest RER values during the dark phase from the mean of the five lowest RER values during the light phase. Caloric consumption was calculated using the following values: HFD $5.24 \mathrm{kcal} / \mathrm{g}$, chow $3.18 \mathrm{kcal} / \mathrm{g}$.

\section{Assessment of mitochondrial function}

Mitochondrial respiration was measured by highresolution respirometry (Oxygraph2k, Oroboros, Austria). Liver mitochondria were isolated according to Frezza et al. (2007). Mitochondrial protein concentration was measured using the Bio-Rad DC protein assay. Permeabilization of skeletal muscle fibers was performed according to Pesta \& Gnaiger (2012). After weighing, muscle fibers were placed in the Oxygraph2k chamber and $\mathrm{O} 2$ concentration was raised to approx. $400 \mu \mathrm{M}$. Substrates, uncoupler, and inhibitors were added to the chambers in the following sequence: malate $(0.05 \mathrm{mM})$, octanoyl-carnitine $(0.2 \mathrm{mM})$, ADP (4 mM final concentration), malate $(2.05 \mathrm{mM}$ final concentration), glutamate $(10 \mathrm{mM})$, succinate $(20 \mathrm{mM})$, carbonyl cyanide-4-(trifluoromethoxy) phenylhydrazone (FCCP, sequential addition of $0.25 \mu \mathrm{M}$ until no further increase in $\mathrm{O} 2$ consumption), rotenone $(0.5 \mu \mathrm{M})$, and antimycin $\mathrm{A}(2.5 \mu \mathrm{M})$ to obtain values for residual oxygen consumption (ROX). $\mathrm{O}_{2}$ flux values were normalized after subtraction of ROX values to wet weight (muscle fibers) or protein concentration (liver mitochondria).

\section{Citrate synthase assay}

Citrate synthase (CS) activity in liver mitochondria and homogenized muscle samples was measured in a microplate format according to Horscroft et al. (2017). Briefly, samples were either homogenized (muscle fibers) or diluted (liver mitochondria) in CS sample buffer (Hepes $20 \mathrm{mM}$, EDTA $1 \mathrm{mM}$, Triton-X100 0.1\% (v/v), protein concentration was measured (Bio-Rad DC protein assay) and adjusted to $10 \mu \mathrm{g} / \mathrm{mL}$ in assay buffer (Tris $100 \mathrm{mM}, \mathrm{pH}$ 8.0, 5,5'-Dithiobis-(2-nitrobenzoic acid) (DTNB) $0.1 \mathrm{mM}$, acetyl coenzyme A (CoA) $0.3 \mathrm{mM}$ ). To start the reaction, oxaloacetate was added to a final concentration of $0.5 \mathrm{mM}$ and the reaction of DTNB with free CoA-SH was monitored spectrophotometrically at $412 \mathrm{~nm}$ (Horscroft et al. 2017).

\section{Statistical analyses}

Strategy: our main aim was to check whether NR supplementation has a differential effect on B6J and B6N mice during HFD feeding. We first analyzed the effect of NR supplementation with supplementation (NR vs no NR) and mouse strain (B6J vs B6N) as factors in HFD-fed and chow-fed mice separately. Since we unexpectedly saw no effect of NR supplementation, but a difference in response to HFD feeding between mouse strains, we then tested for differences using mouse strain (B6J vs B6N) and diet (HFD vs chow) as factors and included mouse data regardless of whether or not mice were supplemented with NR. Tests for statistical significance were done using GraphPad Prism version 9 (GraphPad Software, LLC) with ordinary two-way ANOVA followed by Tukey's multiple comparisons test, except for the time course of body 


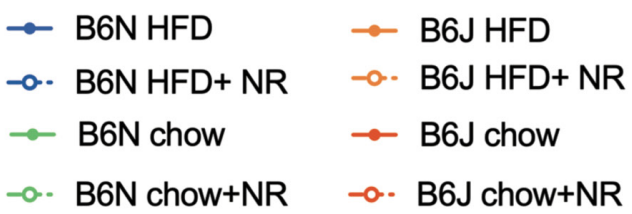

A

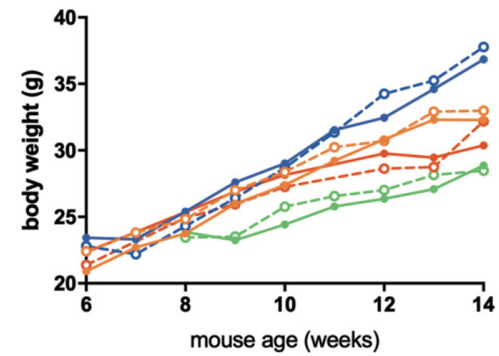

B

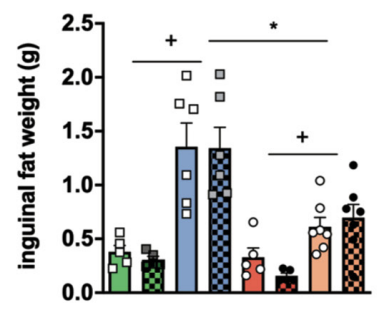

B6N B6J

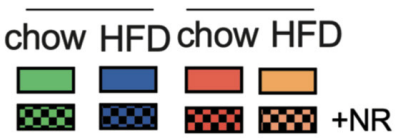

C

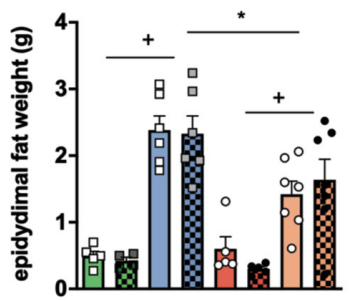

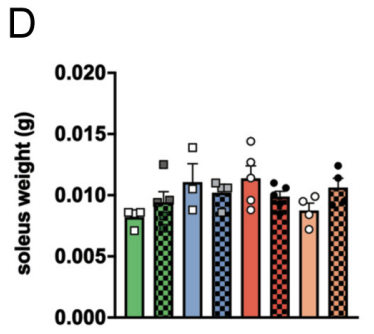
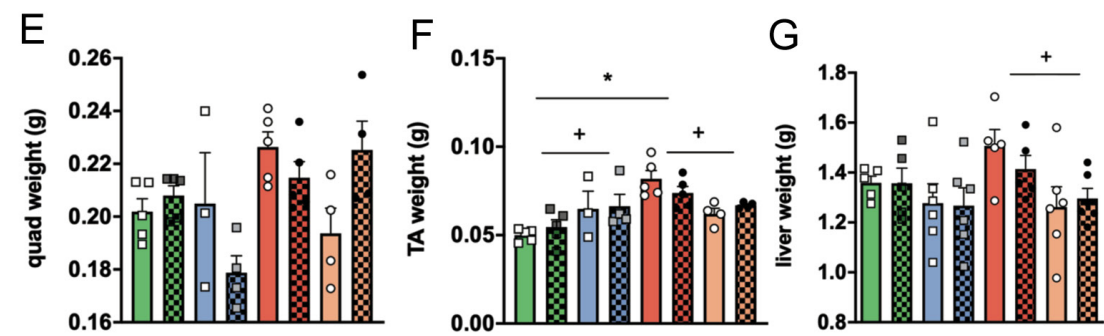

\section{Figure 1}

NR supplementation does not counteract HFD-induced obesity. (A) Bodyweight during 8 weeks of chow or HFD feeding of B6N and B6J mice, (B) inguinal, (C) epididymal fat pad, (D) liver, (E) quadriceps, (F) tibialis anterior, and (G) soleus muscle weight. Data are presented as mean \pm S.E.M., $n=10 \mathrm{HFD}, n=5$ chow for body weight, $n=6 \mathrm{HFD}, n=5$ chow for liver and fat weights, $n=3-5$ for muscle weights. Tests for statistical significance were done using repeated three-way ANOVA, with time, diet, and mouse strain as factors (A) or ordinary two-way ANOVA with diet and mouse strain as factors followed by Tukey's test for multiple comparisons. Data for NR vs no NR supplementation were analyzed together since no significant differences were found for NR vs no NR. ${ }^{+} P<0.05$ for HFD vs chow, ${ }^{*} P<0.05$ for B6J vs B6N.

weight data (Fig. 1A), which were analyzed by repeated three-way ANOVA with time, diet, and mouse strain as factors and for mitochondrial function data, which were analyzed by ordinary two-way ANOVA followed by Tukey's multiple comparisons test, with mouse strain and NR supplementation as factors.

Multiple $t$-tests with Holm-Sidak correction were used for analyzing differences in time courses for energy expenditure and respiratory exchange ratio (RER). Energy expenditure and $\triangle$ RER were analyzed using linear regression and analysis of covariance (ANCOVA) between average absolute daily energy expenditure/ $\triangle R E R$ and body weight (Mina et al. 2018). Differences between the slopes of the lines were determined by linear regression. All data points were included in the analysis. Data are represented as mean \pm S.E.M., statistically significant $(P<0.05)$ differences were marked by + for comparisons between chow and HFD, by * for comparisons between B6J and B6N mouse strains, and by \# for comparisons between NR vs no NR supplementation.

\section{Results}

Body composition, glucose tolerance, and hepatic lipid accumulation were not altered by NR supplementation

Previous studies reported that NR supplementation counteracted negative effects of HFD-induced obesity, decreased fat depot size in HFD-fed mice (Cantó et al. 2012), and prevented HFD-induced impairments in glucose tolerance (Yoshino et al. 2011, Cantó et al. 2012, Trammell et al. 2016). We examined the impact of supplementation with NR on body and organ weight, fat depot weight, glucose tolerance, and lipid accumulation in the liver of B6N mice in comparison to $\mathrm{B} 6 \mathrm{~J}$ mice when fed standard chow and after HFD feeding. NR supplementation neither altered weight gain (Fig. 1A) nor affected the weight of adipose tissue depots, liver, and different muscles (Fig. $1 \mathrm{~B}, \mathrm{C}, \mathrm{D}, \mathrm{E}, \mathrm{F}$ and $\mathrm{G})$. In contrast, marked differences were detected in body weight gain of HFD-fed B6J vs B6N

This work is licensed under a Creative Commons Attribution 4.0 International License. 
(Supplementary Fig. 1E). While B6N mice on HFD had a significantly higher body weight than B6N chow-fed mice starting from week 9, B6 J mice on HFD differed from chow-fed B6J only in week 13 . There was a significant difference in final weight (week 14) of HFD-fed B6N and B6J mice, while chow-fed B6N and B6J mice did not differ significantly. Fat depot weights of HFD-fed mice were higher than chow-fed mice, while HFD-fed B6N had a higher increase in fat depot weight than B6J mice (Fig. 1B and C). These differences persisted also when weights were normalized to body weight (Supplementary Fig. 1F and $\mathrm{G})$. Soleus and quadriceps muscle were not significantly different in weight (Fig. 1D and E), while tibialis anterior muscle weight was higher in chow than in HFD-fed mice and in $\mathrm{B} 6 \mathrm{~J}$ vs $\mathrm{B} 6 \mathrm{~N}$ chow-fed mice (Fig. $1 \mathrm{~F},+P<0.05 \mathrm{~B} 6 \mathrm{~J} \mathrm{HFD}$ vs chow-fed mice, ${ }^{*} P<0.05$ chow-fed B6J vs B6N). The liver weight of B6J chow-fed mice was higher than B6J HFD-fed mice (Fig. $1 \mathrm{G},+P<0.05$ B6J HFD vs chow-fed mice).

HFD feeding for 8 weeks (Fig. 2A, B and C) induced a marked glucose intolerance both in $\mathrm{B} 6 \mathrm{~N}$ and $\mathrm{B} 6 \mathrm{~J}$ mice regardless of NR supplementation compared to chow- fed mice as measured by area under the curve (Fig. 2C, $+P<0.05$ HFD vs chow-fed mice). After 8 weeks, HFD-fed mice of both strains had higher fasting blood glucose levels than mice on chow feed, while HFD-fed B6J mice displayed increased fasting blood glucose levels compared to HFD-fed B6N (Fig. 2D, $+P<0.05$ HFD vs chow-fed mice, ${ }^{*} P<0.05$ HFD-fed B6J vs B6N).

HFD-induced obesity is associated with increased hepatic lipid accumulation. NR supplementation did not decrease lipid accumulation in any experimental group. B6N mice on HFD stored significantly more hepatic lipids than chow-fed B6N mice or HFD-fed B6J, while there was no significant difference between HFD and chow-fed B6J mice (Fig. $2 \mathrm{E}$ and $\mathrm{F},+P<0.05 \mathrm{~B} 6 \mathrm{~N}$ HFD vs chow; ${ }^{*} P<0.05$ HFD-fed B6J vs B6N).

\section{Energy metabolism is not influenced by NR supplementation}

NR supplementation has been shown to enhance oxidative metabolism and energy expenditure in HFD-fed mice

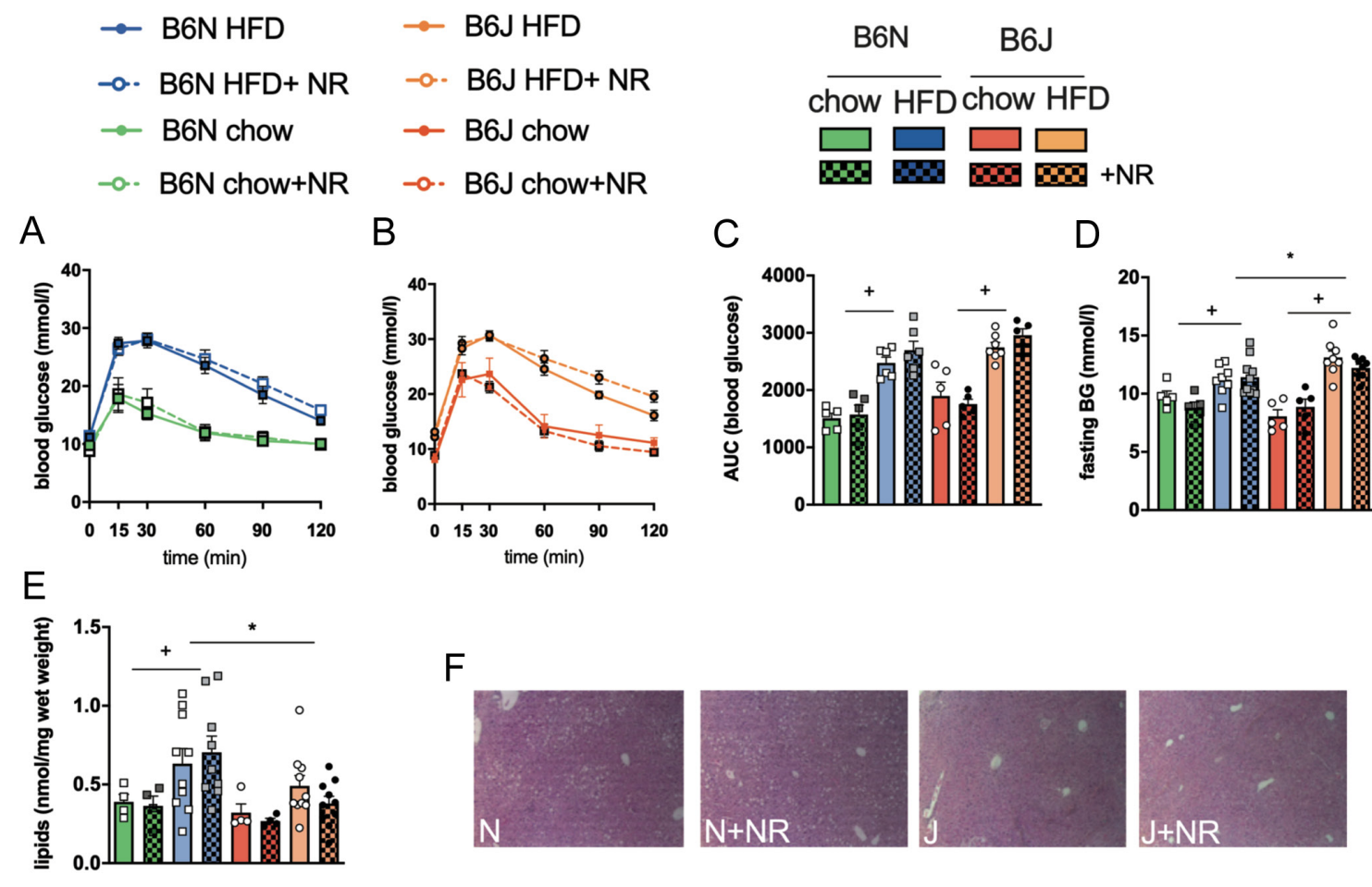

Figure 2

NR supplementation does not counteract HFD-induced glucose intolerance. Glucose tolerance after 8 weeks of chow or HFD feeding was assessed by i.p. glucose tolerance test with $2 \mathrm{~g}$ glucose/ $\mathrm{kg}$ body weight after $5 \mathrm{~h}$ of fasting. Time course of blood glucose concentrations is shown in (A) B6N and (B) B6 mice and quantified in (C) area under the curve (AUC) $n=6-7 \mathrm{HFD}, n=5$ chow, (D) fasting blood glucose (BG) $n=8-10 \mathrm{HFD}, n=5$ chow. (E) Hepatic lipid accumulation after 8 weeks of HFD or chow feeding, (F) representative images of H\&E stained liver tissue sections (magnification 20×) of HFD-fed B6N and J mice. Data are presented as mean \pm S.E.M., $n=9-10 \mathrm{HFD}, n=4$ chow. Tests for statistical significance were done using ordinary two-way ANOVA with diet and mouse strain as factors followed by Tukey's test for multiple comparisons. Data for NR vs no NR supplementation were analyzed together since no significant differences were found for NR vs no NR. ${ }^{+} P<0.05$ for HFD vs chow, $* P<0.05$ for B6J vs B6N. 
(Cantó et al. 2012). To test whether NR supplementation influenced the metabolic phenotype in our experimental setup, mice underwent indirect calorimetry measurements after 8 weeks of NR-supplemented or non-supplemented chow or HFD feeding. NR supplementation did not significantly affect energy expenditure in $\mathrm{B} 6 \mathrm{~N}$ or $\mathrm{B} 6 \mathrm{~J}$ mice regardless of diet (Fig. 3A, B, C and D). During the active phase, we observed a higher energy expenditure in B6J compared to B6N mice $(P<0.05$ for chow-fed mice; $P=0.06$ for HFD-fed mice). Chow-fed B6J mice had higher body weights than $\mathrm{B} 6 \mathrm{~N}$ on the chow diet as opposed to HFD-fed B6J mice, which had lower body weights than HFD-fed B6N mice (Fig. 3G). Interaction analysis showed a significant influence of body weight on energy expenditure in HFD-fed (Fig. 3F), but not chow-fed mice (Fig. 3E).

NR supplementation did not influence the respiratory exchange ratio (RER). The RER was higher in chow-fed than HFD-fed mice and indicated a preferential use of lipids after 8 weeks of HFD (Fig. 4A, B, C and D). As expected, metabolic flexibility as measured by the difference of RER between night and day ( $\triangle \mathrm{RER}$ ) was higher in chow-fed than HFD-fed mice (Fig. 4E) and not influenced by mouse strain. Bodyweight did not influence $\triangle$ RER, as shown by ANCOVA (Supplementary Fig. 2A and B).

Except for a borderline significantly higher caloric consumption in chow-fed vs HFD-fed B6J mice (Fig. 5A), there were no differences on either diet during night and day (Fig. 5A and D). In contrast, we found significant differences both in water intake (Fig. 5B) and feeding frequency (Fig. 5C) during the active phase and for B6N mice during the resting phase (Fig. 5E and F). Chow-fed mice of both strains had a higher water intake (Fig. 5B $+P<0.05$ for HFD vs chow-fed) and were more active as indicated by feeding frequency (Fig. 5C, $+P<0.05$ for HFD vs chow-fed). B6J mice drank significantly more water compared to $\mathrm{B} 6 \mathrm{~N}$ both on chow and on HFD during the night (Fig. $5 \mathrm{~B},{ }^{*} \mathrm{P}<0.05$ for B6J vs B6N) and also were more active (Fig. $5 \mathrm{C},+P<0.05$ for HFD vs chow-fed).

\section{NR supplementation induced increases in mitochondrial respiration in permeabilized soleus muscle fibers}

NR supplementation was previously shown to improve mitochondrial function in the liver and muscle of obese mice (Cantó et al. 2012). We measured respiration in the liver mitochondria and different permeabilized muscle fibers in mice after 8 weeks of HFD with and without NR supplementation. We found higher respiration in soleus muscle fibers of NR-supplemented mice for B6J mice
(Fig. 6A, B and C), specifically when mitochondria were supplied with substrates for complexes I and II and ADP (Fig. $6 \mathrm{~B},{ }^{\#} P<0.05$ for NR vs no NR) or when respiration was uncoupled (Fig. 6C, $\# P<0.05$ for NR vs no NR). Mitochondrial respiration of tibialis anterior (TA) muscle fibers (Fig. 6E, F and G) or liver mitochondria (Fig. 6I, J and K) was not significantly influenced by NR supplementation. Citrate synthase activity was not significantly different in any tissue (Fig. 6D, H and L), indicating that mitochondrial mass was not changed by NR supplementation.

\section{Discussion}

We asked whether the metabolic responses to supplementation with NR could be influenced by the choice of mouse strain and compared C57B/B6J with C57B/B6N mice, both of which are established inbred mouse strains for the study of diet-induced obesity (Podrini et al. 2013). B6N mice differ from B6J in a number of single nucleotide polymorphisms that may influence the development of obesity, such as Snap29 and Aplp2 (Heiker et al. 2013, Smoczek et al. 2020). In addition, B6N, in contrast to B6J, is functional for nicotinamide nucleotide transhydrogenase (Nnt) (Mekada et al. 2009). This mitochondrial enzyme catalyzes the conversion of reduced NADH to reduced NADPH and, therefore, is crucial for mitochondrial redox balance and oxidative stress defense (Ronchi et al. 2013, 2016, Fisher-Wellman et al. 2015, Navarro et al. 2017), while Nnt's role in insulin secretion is not yet clear (Toye et al. 2005, Freeman et al. 2006, Aston-Mourney et al. 2007, Fisher-Wellman et al. 2016). Numerous studies on repleting NAD by supplementation with NR showed beneficial effects on mitochondrial function and energy metabolism in mouse models of metabolic and mitochondrial disease (Cantó et al. 2012, Felici et al. 2015, Lee et al. 2015, Trammell et al. 2016, Zhou et al. 2016, Schöndorf et al. 2018, Crisol et al. 2020, Han et al. 2019). Male C57B/6J mice were used in most of these studies to model obesity, type 2 diabetes, and metabolic dysfunction.

We subjected both B6J and B6N mice to 8 weeks of HFD, which is a well-described regimen to induce a mild obesity phenotype and impaired glucose tolerance (de Wilde et al. 2009, Naznin et al. 2017, Zhou et al. 2017, Chang et al. 2018). Unexpectedly, B6J mice did not gain as much weight as B6N. This was reflected by a seemingly higher capacity of $\mathrm{B} 6 \mathrm{~N}$ mice to store fat both in adipose tissue depots and in the liver. Other studies examining HFD-induced obesity reported conflicting results regarding weight gain of B6J mice (Koza et al. 2006, Nicholson et al. 2010, Boulangé 

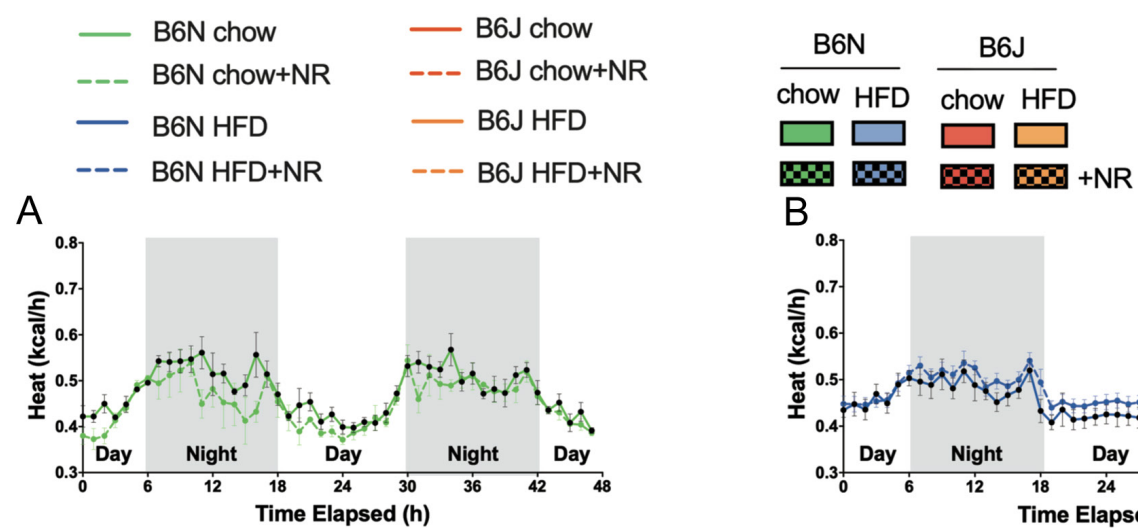

B
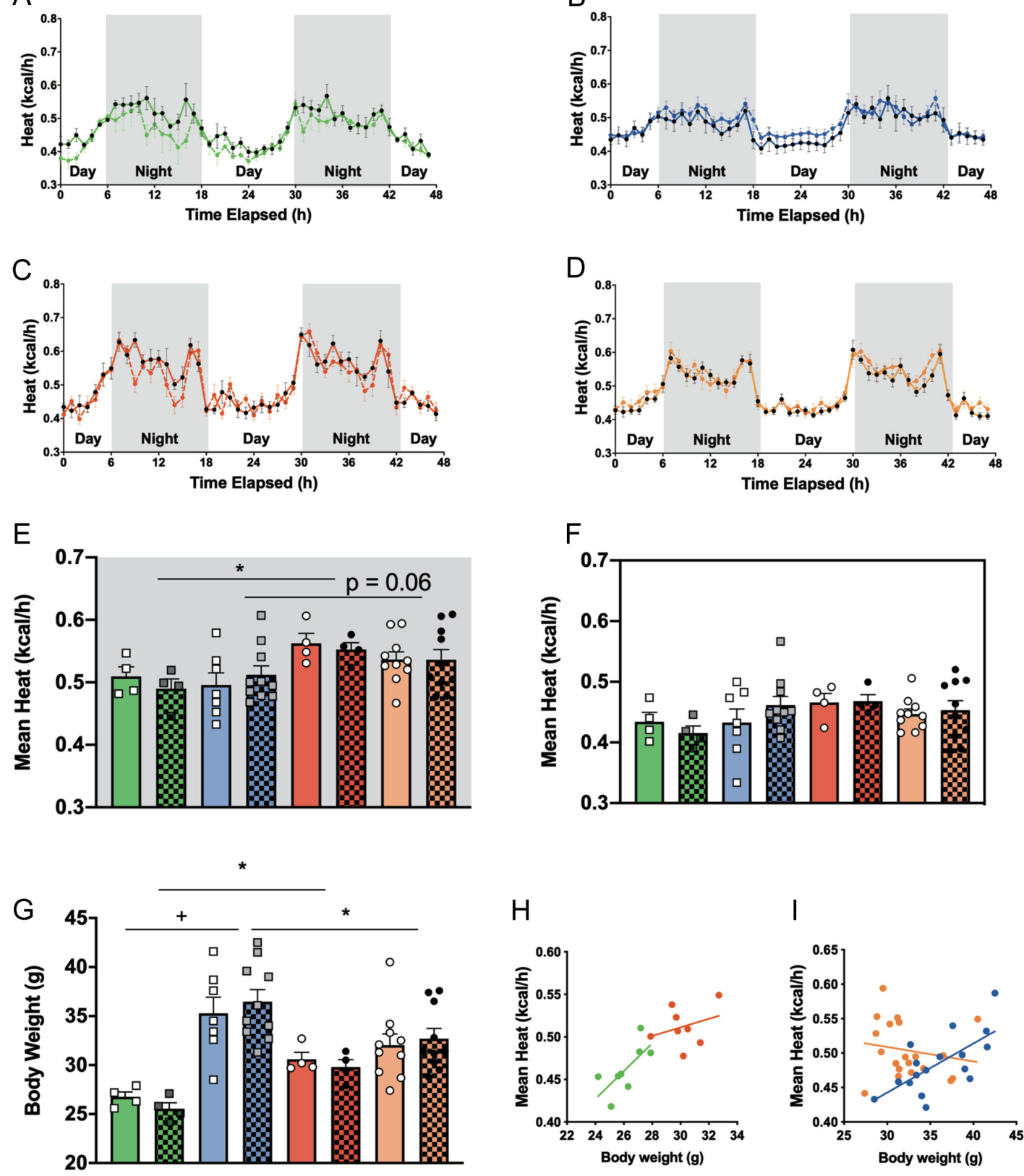

\section{Figure 3}

NR supplementation does not affect energy expenditure in B6N or B6J mice. Energy expenditure was determined by indirect calorimetry in metabolic cages. The time course of the energy expenditure measurement is shown in (A) chow-fed B6N, (B) chow-fed B6J, (C) HFD-fed B6N, (D) HFD-fed B6J. Differences were tested by multiple $t$-tests with Holm-Sidak correction. Differences in average energy expenditure between chow-fed and HFD-fed B6N and B6J mice are shown for (E) the active phase/night and (F) the resting phase/day, body weights at the start of indirect calorimetry assessment are shown in (G) ( $n=4$ for chow, $n=7$ for B6N HFD, $n=10$ for B6N HFD+NR, B6J HFD and HFD+NR). The relationship between average nightly energy expenditure and body weight is depicted for B6J and B6N mice when chow-fed (H) and (I) HFD ( $n=8$ for chow, $n=17$ for B6N HFD, $n=20$ for B6J HFD). Data are presented as mean \pm S.E.M. Tests for statistical significance were done using ordinary two-way ANOVA with diet and mouse strain as factors followed by Tukey's test for multiple comparisons. Data for NR vs no NR supplementation were analyzed together since no significant differences were found for NR vs no NR. ${ }^{+} P<0.05$ for HFD vs chow, ${ }^{*} P<0.05$ for B6J vs B6N Linear regression and analysis of covariance (ANCOVA) was done between average nightly energy expenditure and body weight. Slopes of HFD-fed mice were significantly different $(P<0.05)$. 


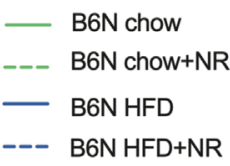

A

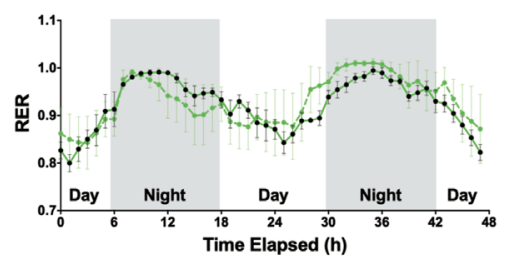

C
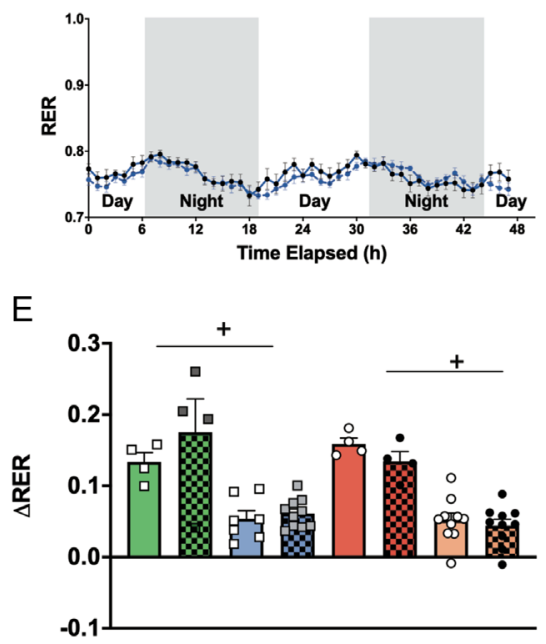

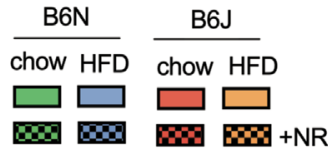

B

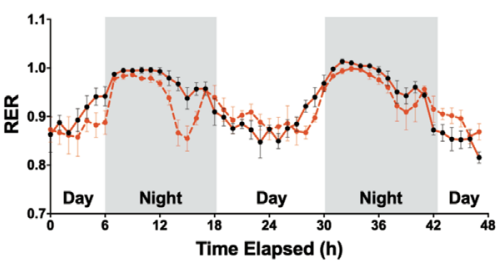

D

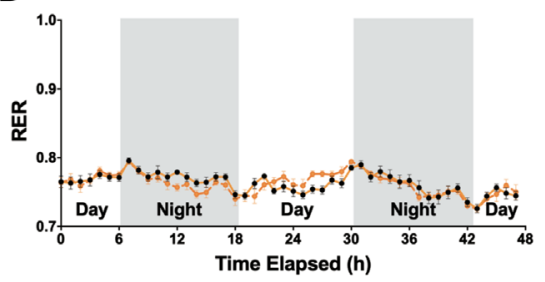

Figure 4

Substrate usage is not altered by NR supplementation. The respiratory exchange ratio (RER) as a measure for substrate usage was determined by indirect calorimetry in metabolic cages. The time course of RER measurement is shown in (A) chow-fed B6N, (B) chow-fed B6J, (C) HFD-fed B6N, and (D) HFD-fed B6J mice. $\triangle R E R$ as a measure for metabolic flexibility was calculated by subtracting the five lowest values during the day from the five highest values during the night and is shown in (E). Data are presented as mean \pm S.E.M., $n=4$ for chow, $n=7$ for B6N HFD, $n=10$ for B6N HFD+NR, B6J HFD, and HFD+NR. Tests for statistical significance were done using ordinary two-way ANOVA with diet and mouse strain as factors followed by Tukey's test for multiple comparisons. Data for NR vs no NR supplementation were analyzed together since no significant differences were found for NR vs no NR. ${ }^{+} P<0.05$ for HFD vs chow.
B6N B6J

chow HFD chow HFD

\section{$\square$ एक $\square$ +NR}

A

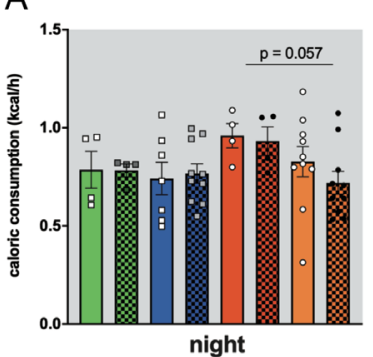

B

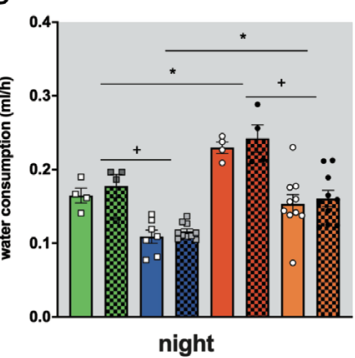

C

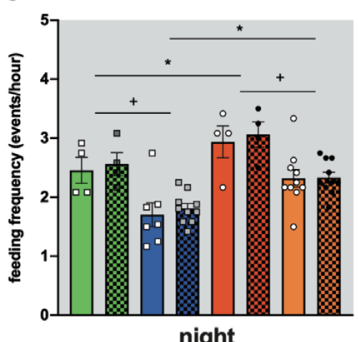

night

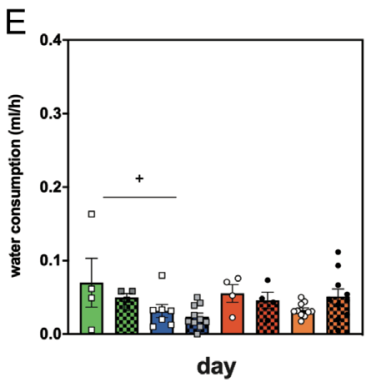

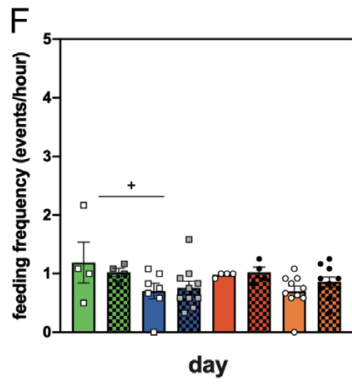

\section{Figure 5}

Water intake and feeding frequency are altered by NR supplementation in HFD-fed mice. Caloric consumption ( $A$ and $C$ ) and water intake ( $B$ and $D$ ) as well as feeding frequency ( $\mathrm{C}$ and $\mathrm{F}$ ) as a measure for activity were determined by indirect calorimetry in metabolic cages. Upper panel: night/active phase, lower panel: day/resting phase. Data are presented as mean \pm S.E.M., $n=4$ for chow, $n=7$ for B6N HFD, $n=10$ for B6N HFD+NR, B6J HFD, and HFD+NR. Tests for statistical significance were done using ordinary two-way ANOVA with diet and mouse strain as factors followed by Tukey's test for multiple comparisons. Data for NR vs no NR supplementation were analyzed together since no significant differences were found for NR vs no NR. ${ }^{+} P<0.05$ for HFD vs chow, ${ }^{*} P<0.05$ for B6] vs $\mathrm{B} 6 \mathrm{~N}$. https://joe.bioscientifica.com https://doi.org/10.1530/JOE-21-0123 (c) 2021 The authors Published by Bioscientifica Ltd.
Printed in Great Britain 

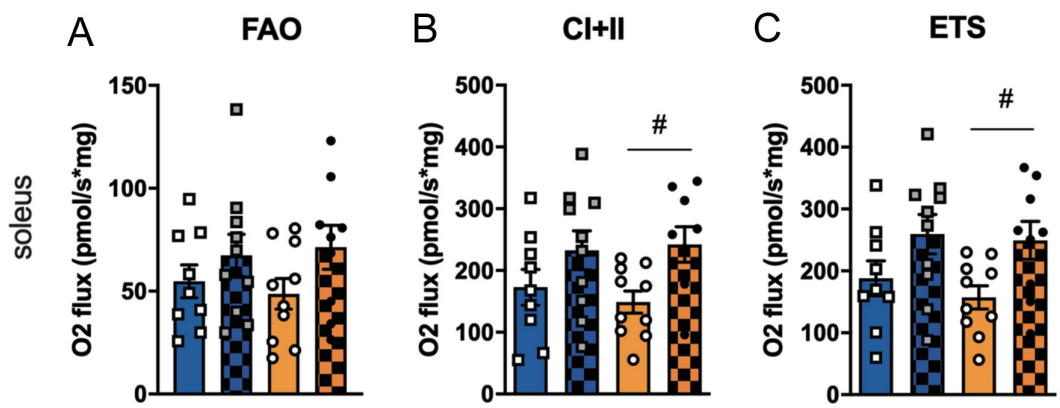

D Cs
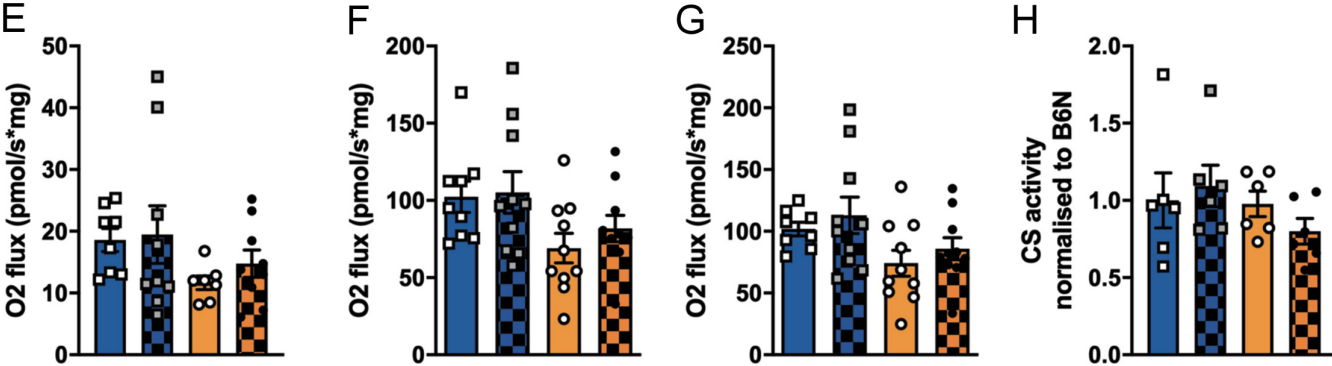

I

$\mathrm{J}$

$\mathrm{K}$

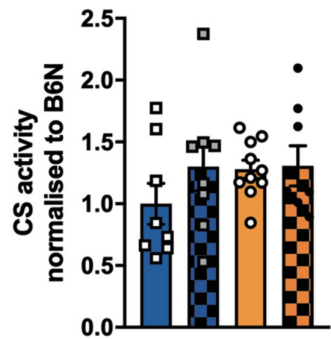

B6N B6J

HFD HFD
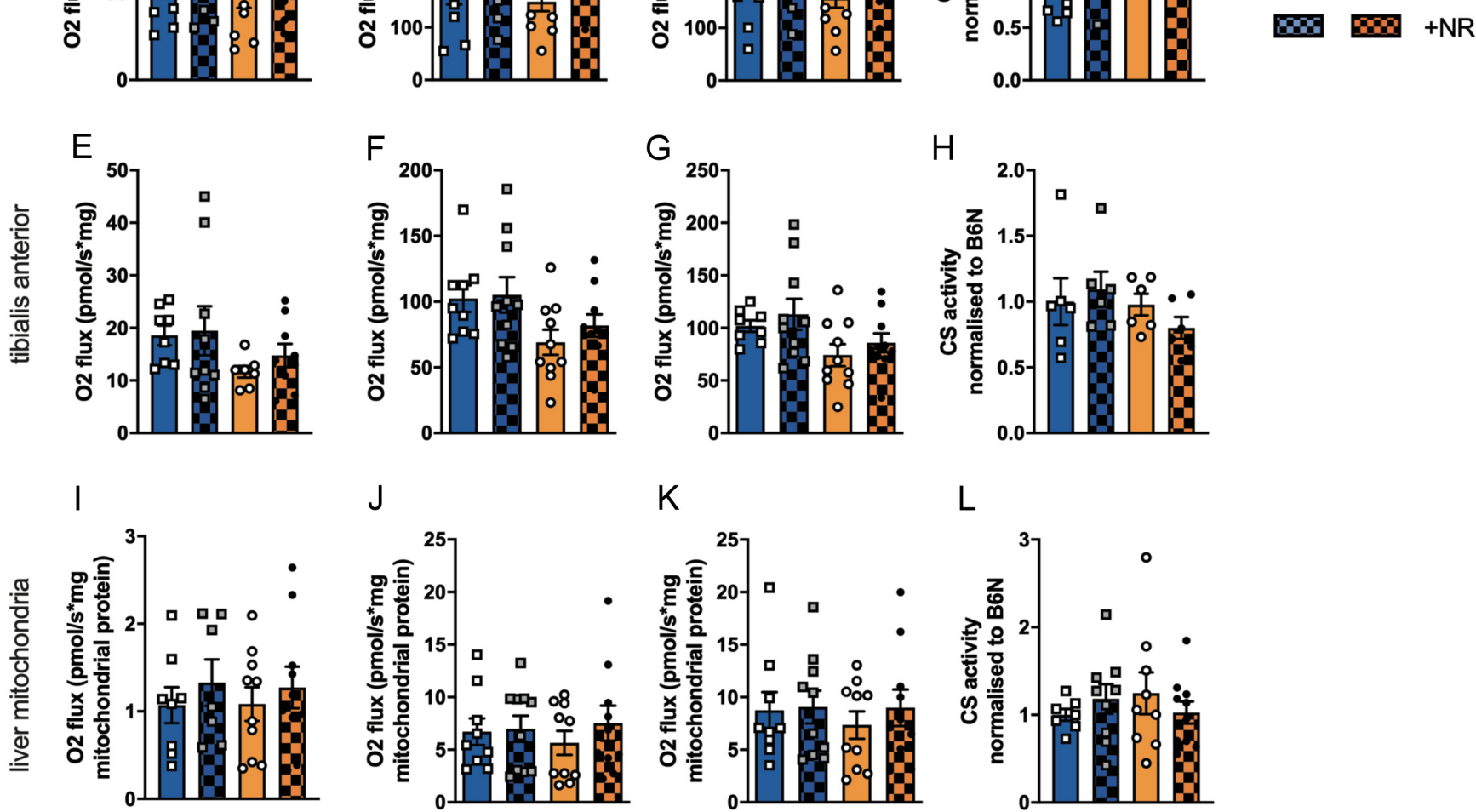

L

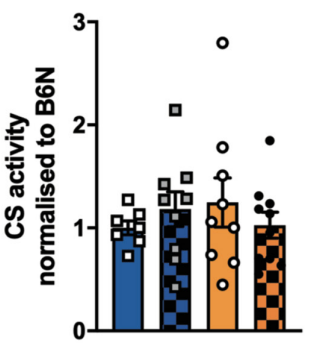

Figure 6

Mitochondrial respiration is higher in soleus muscle fibers from NR-supplemented compared to non-supplemented HFD-fed mice. Soleus and tibialis anterior permeabilized muscle fibers as well as liver mitochondria were subjected to high-resolution respirometry in the presence of ADP, $n=9-10$ per group. FAO, fatty acid (octanoyl-carnitine) oxidation, $\mathrm{Cl}+\mathrm{Il}$ oxidation of octanoyl-carnitine, malate, and glutamate, ETS electron transport system maximum respiratory capacity induced by uncoupling of mitochondria with carbonyl cyanide-p-trifluoromethoxyphenylhydrazone (FCCP). CS, citrate synthase activity was measured enzymatically, $n=6$ per group. Data are presented as mean \pm S.E.M. Tests for statistical significance were done using ordinary two-way ANOVA with NR supplementation and mouse strain as factors followed by Tukey's correction for multiple comparisons. $\# P<0.05$ for NR vs no NR.

et al. 2013, Kahle et al. 2013, Fisher-Wellman et al. 2016). As expected and described before, we detected higher blood glucose levels during a glucose tolerance test in B6J and B6N mice after 8 weeks of HFD (Nicholson et al. 2010, Fontaine \& Davis 2016) compared to chow.

In contrast to other studies (Cantó et al. 2012, Trammell et al. 2016), we did not detect a decrease in body weight, weight of fat depots, or improvement of glucose metabolism in NR-supplemented animals. Mice received $3.0 \mathrm{mg} / \mathrm{mL} \mathrm{NR}$ in drinking water, which is equivalent to approximately $500 \mathrm{mg} / \mathrm{kg} /$ day and resulted in an approximate daily uptake of NR of 14-18 mg for chow and 7-10 mg for HFD-fed mice. NR concentration and mode of uptake were similar to other studies, which reported increased NAD, NADH, and ATP concentrations in the liver of NR-supplemented animals (Mukherjee et al. 2017, 2021). Using this dose, a beneficial effect on liver regeneration following partial hepatectomy was observed by Mukherjee et al (Mukherjee et al. 2017). To study the effects of NR supplementation in feed, a dose of $400-450 \mathrm{mg} / \mathrm{kg} /$ day was used in several mouse studies and beneficial effects on mitochondrial function, energy metabolism, muscle stem cell regeneration, and cardiac function were observed (Cantó et al. 2012, Gariani et al. 2016, Ryu et al. 2016, Diguet et al. 2018).

Since B6J mice on HFD drank more water than B6N, their exposure to NR was potentially higher. Similarly, chow-fed mice drank more water than HFD-fed mice of both strains. Our study is limited in that we could not 
measure NAD of B6N NR-supplemented in comparison to non-supplemented mice due to limited sample availability. When checking total NAD in the liver and cardiac muscle of B6J HFD-fed mice, we saw a significant increase. Another limitation of the study is the small number of mice on chow diet, which potentially led to false-negative results regarding the effect of NR supplementation on energy expenditure and RER.

In previous studies, NR supplementation was shown to be effective in mice with strong obesity or diabetic phenotype (Cantó et al. 2012, Trammell et al. 2016). Our mice were on a HFD for 8 weeks to model early phase weight gain and changes in glucose tolerance and energy metabolism (Rendina-Ruedy et al. 2015). The phenotypic changes, therefore, were slighter than for mice on a 21-week-HFD (Trammell et al. 2016) or on a high-fat highsucrose diet (Cantó et al. 2012, Gariani et al. 2016). The validity of comparing results from this study of NR effects in mice with NR supplementation studies in humans is obviously limited. Similarly to our results though, NR supplementation in mildly obese or aged subjects did not result in substantial improvements in energy metabolism, had no effect on endocrine pancreatic function or on skeletal muscle mitochondrial function (Dollerup et al. 2018, 2019a,b, Martens et al. 2018, Elhassan et al. 2019).

Few animal studies also reported no benefits (Purhonen et al. 2018, Spaulding et al. 2019, Frederick et al. 2020) or even detrimental effects induced by NR supplementation, such as decreased exercise capacity and systemic oxidative stress in rats (Kourtzidis et al. 2016, 2018), decreased metabolic flexibility in mice (Shi et al. 2017) or glucose intolerance and white adipose tissue dysfunction in mice (Shi et al. 2019). In some of these studies, NR was used at lower doses as in our experiments. Specifically, Shi etal. used NR supplementation at $900 \mathrm{mg}$ NR per $\mathrm{kg}$ diet, which corresponds to an NR dose of approx. $100 \mathrm{mg} / \mathrm{kg} /$ day and detected no beneficial effects on energy metabolism. Instead, compromised metabolic flexibility (the ability to rapidly switch metabolism between carbohydrate oxidation and fatty acid oxidation) was found by indirect calorimetry (Shi et al. 2017). At the ten-fold NR dose (9000 mg NR/kg diet), Shi et al. observed a decreased glucose clearance rate accompanied by an impaired insulin response along with the decreased metabolic flexibility. This observation was probably due to reduced insulin responsiveness and increased inflammation of epidydimal white adipose tissue in NR-supplemented compared to control mice. In contrast to our 8 week study, mice received a high dose of NR for 18 weeks (Shi et al. 2019).

When comparing mitochondrial respiration in supplemented vs non-supplemented mice on HFD, we detected increased ADP-dependent and uncoupled respiration in soleus muscle fibers from NR-supplemented to non-supplemented B6J mice, with a similar trend seen in B6N. NR did not influence the activity of citrate synthase as a measure for mitochondrial mass. In a previous study, soleus was shown to take up nicotinamide mononucleotide (NMN) and subsequently increase mitochondrial respiration (Mills et al. 2016). The response to HFD was shown to be fiber-type selective (Pinho et al. 2017, Leduc-Gaudet et al. 2018). Whether soleus fibers are more responsive to NR, take up more NR, or more sufficiently replete NAD when supplemented with NR should be determined in future studies.

In our hands, the beneficial effects of NR supplementation reported for HFD-induced obesity mouse models were not apparent. We only detected slight mouse-strain-dependent variation in the response to NR supplementation. In line with this, a recent study examining indirect calorimetry results from two large mouse projects revealed the institutional site as causing the biggest experimental variance (Corrigan et al. 2020). The prominent differences in metabolic phenotype in our study were seen between the two mouse strains, highlighting once more the importance of checking metabolic effects of nutritional supplements in multiple mouse strains.

\section{Supplementary materials}

This is linked to the online version of the paper at https://doi.org/10.1530/ JOE-21-0123.

\section{Declaration of interest}

The authors declare that there is no conflict of interest that could be perceived as prejudicing the impartiality of the research reported.

\section{Funding}

This work was funded by the European Union, grant number 705869, a Wellcome Trust Senior Fellowship, grant number GGL-104612/Z/14/Z, an Early Career Grant from the Society for Endocrinology and received support from the Research and Development Fund of the College of Medical and Dental Sciences, University of Birmingham, UK.

\section{Author contribution statement}

Conceptualization, A G, D J H and G G L; methodology, A G, D M C, L O, R S F, C L D, S H, D P L, D N, D J H.; formal analysis, A G; investigation, D M C, L O, R S F, C L D, S H, D P L; C E B, S R H; resources, G G L; writing - original draft preparation, A G; writing - review and editing, A G; visualization, A G; supervision, D J H and G G L; project administration, A G and G G L; funding acquisition, A G and G G L. 


\section{Acknowledgements}

The authors thank Prof Marie Migaud for helpful comments on nicotinamide riboside in drinking water, Dr Katarina Kluckova for help with respirometry analysis, and members of the IMSR for helpful discussion. The authors thank ChromaDex (Irvine, California) for providing nicotinamide riboside.

\section{References}

Aston-Mourney K, Wong N, Kebede M, Zraika S, Balmer L, McMahon JM, Fam BC, Favaloro J, Proietto J, Morahan G, et al. 2007 Increased nicotinamide nucleotide transhydrogenase levels predispose to insulin hypersecretion in a mouse strain susceptible to diabetes. Diabetologia 50 2476-2485. (https://doi.org/10.1007/s00125-007-0814-x)

Boulangé CL, Claus SP, Chou CJ, Collino S, Montoliu I, Kochhar S, Holmes E, Rezzi S, Nicholson JK, Dumas ME, et al. 2013 Early metabolic adaptation in C57BL/6 mice resistant to high fat diet induced weight gain involves an activation of mitochondrial oxidative pathways. Journal of Proteome Research 12 1956-1968. (https://doi.org/10.1021/ pr400051s)

Cantó C, Houtkooper RH, Pirinen E, Youn DY, Oosterveer MH, Cen Y, Fernandez-Marcos PJ, Yamamoto H, Andreux PA, Cettour-Rose P, et al. 2012 The $\mathrm{NAD}(+)$ precursor nicotinamide riboside enhances oxidative metabolism and protects against high-fat diet-induced obesity. Cell Metabolism 15 838-847. (https://doi.org/10.1016/j.cmet.2012.04.022)

Chang CJ, Lu CC, Lin CS, Martel J, Ko YF, Ojcius DM, Wu TR, Tsai YH, Yeh TS, Lu JJ, et al. 2018 Antrodia cinnamomea reduces obesity and modulates the gut microbiota in high-fat diet-fed mice. International Journal of Obesity 42 231-243. (https://doi.org/10.1038/ijo.2017.149)

Corrigan JK, Ramachandran D, He Y, Palmer C, Jurczak MJ, Li B, Friedline RH, Kim JK, Ramsey JJ, Lantier L, et al. 2020 A big-data approach to understanding metabolic rate and response to obesity in laboratory mice. eLife 9 e53560. (https://doi.org/10.7554/eLife.53560)

Crisol BM, Veiga CB, Braga RR, Lenhare L, Baptista IL, Gaspar RC, Muñoz VR, Cordeiro AV, da Silva ASR, Cintra DE, et al. 2020 NAD $^{+}$ precursor increases aerobic performance in mice. European Journal of Nutrition 59 2427-2437. (https://doi.org/10.1007/s00394-019-02089-z)

de Castro JM, Assumpção JAF, Stein DJ, Toledo RS, da Silva LS, Caumo W, Carraro CC, da Rosa Araujo AS \& Torres ILS 2020 Nicotinamide riboside reduces cardiometabolic risk factors and modulates cardiac oxidative stress in obese Wistar rats under caloric restriction. Life Sciences 263 118596. (https://doi.org/10.1016/j.lfs.2020.118596)

de Wilde J, Smit E, Mohren R, Boekschoten MV, de Groot P, van den Berg SAA, Bijland S, Voshol PJ, van Dijk KW, de Wit NWJ, et al. 2009 An 8-week high-fat diet induces obesity and insulin resistance with small changes in the muscle transcriptome of C57BL/6J mice. Journal of Nutrigenetics and Nutrigenomics 2 280-291. (https://doi. org/10.1159/000308466)

Diguet N, Trammell SAJ, Tannous C, Deloux R, Piquereau J, Mougenot N Gouge A, Gressette M, Manoury B, Blanc J, et al. 2018 Nicotinamide riboside preserves cardiac function in a mouse model of dilated cardiomyopathy. Circulation 137 2256-2273. (https://doi.org/10.1161/ CIRCULATIONAHA.116.026099)

Dollerup OL, Christensen B, Svart M, Schmidt MS, Sulek K, Ringgaard S, Stødkilde-Jørgensen H, Møller N, Brenner C, Treebak JT, et al. 2018 A randomized placebo-controlled clinical trial of nicotinamide riboside in obese men: safety, insulin-sensitivity, and lipid-mobilizing effects. American Journal of Clinical Nutrition 108 343-353. (https://doi. $\operatorname{org} / 10.1093 /$ ajcn/nqy132)

Dollerup OL, Chubanava S, Agerholm M, Søndergård SD, Altıntaş A, Møller AB, Høyer KF, Ringgaard S, Stødkilde-Jørgensen H, Lavery GG, et al. 2019a Nicotinamide riboside does not alter mitochondrial respiration, content or morphology in skeletal muscle from obese and insulin resistant men. Journal of Physiology 598 731-754. (https://doi. org/10.1113/JP278752)
Dollerup OL, Trammell SAJ, Hartmann B, Holst JJ, Christensen B, Møller N, Gillum MP, Treebak JT \& Jessen N 2019b Effects of nicotinamide riboside on endocrine pancreatic function and incretin hormones in obese, non-diabetic men. Journal of Clinical Endocrinology and Metabolism 104 5703-5714. (https://doi.org/10.1210/jc.201901081)

Elhassan YS, Kluckova K, Fletcher RS, Schmidt MS, Garten A, Doig CL, Cartwright DM, Oakey L, Burley CV, Jenkinson N, et al. 2019 Nicotinamide riboside augments the aged human skeletal muscle $\mathrm{NAD}^{+}$metabolome and induces transcriptomic and anti-inflammatory signatures. Cell Reports 28 1717.e6-1728.e6. (https://doi.org/10.1016/j. celrep.2019.07.043)

Felici R, Lapucci A, Cavone L, Pratesi S, Berlinguer-Palmini R \& Chiarugi A 2015 Pharmacological NAD-boosting strategies improve mitochondrial homeostasis in human complex I-mutant fibroblasts. Molecular Pharmacology 87 965-971. (https://doi.org/10.1124/mol.114.097204)

Fisher-Wellman KH, Lin CT, Ryan TE, Reese LR, Gilliam LAA, Cathey BL, Lark DS, Smith CD, Muoio DM \& Neufer PD 2015 Pyruvate dehydrogenase complex and nicotinamide nucleotide transhydrogenase constitute an energy-consuming redox circuit. Biochemical Journal 467 271-280. (https://doi.org/10.1042/BJ20141447)

Fisher-Wellman KH, Ryan TE, Smith CD, Gilliam LAA, Lin CT, Reese LR, Torres MJ \& Neufer PD 2016 A direct comparison of metabolic responses to high fat diet in C57BL/6J and C57BL/6NJ mice. Diabetes 65 3249-3261. (https://doi.org/10.2337/db16-0291)

Fontaine DA \& Davis DB 2016 Attention to background strain is essential for metabolic research: C57BL/6 and the International Knockout Mouse Consortium. Diabetes 65 25-33. (https://doi.org/10.2337/db150982)

Frederick DW, McDougal AV, Semenas M, Vappiani J, Nuzzo A, Ulrich JC, Becherer JD, Preugschat F, Stewart EL, Sévin DC, et al. 2020 Complementary $\mathrm{NAD}^{+}$replacement strategies fail to functionally protect dystrophin-deficient muscle. Skeletal Muscle 1030 . (https://doi. org/10.1186/s13395-020-00249-y)

Freeman HC, Hugill A, Dear NT, Ashcroft FM \& Cox RD 2006 Deletion of nicotinamide nucleotide transhydrogenase: a new quantitive trait locus accounting for glucose intolerance in C57BL/6J mice. Diabetes 55 2153-2156. (https://doi.org/10.2337/db06-0358)

Frezza C, Cipolat S \& Scorrano L 2007 Organelle isolation: functional mitochondria from mouse liver, muscle and cultured filroblasts. Nature Protocols 2 287-295. (https://doi.org/10.1038/nprot.2006.478)

Gariani K, Menzies KJ, Ryu D, Wegner CJ, Wang X, Ropelle ER, Moullan N, Zhang H, Perino A, Lemos V, et al. 2016 Eliciting the mitochondrial unfolded protein response via $\mathrm{NAD}(+)$ repletion reverses fatty liver disease. Hepatology 63 1190-1204. (https://doi. org/10.1002/hep.28245)

Han X, Bao X, Lou Q, Xie X, Zhang M, Zhou S, Guo H, Jiang G \& Shi Q 2019 Nicotinamide riboside exerts protective effect against aging-induced NAFLD-like hepatic dysfunction in mice. PeerJ 7 e7568. (https://doi. org/10.7717/peerj.7568)

Heiker JT, Kern M, Kosacka J, Flehmig G, Stumvoll M, Shang E, Lohmann T, Dreßler M, Kovacs P, Blüher M, et al. 2013 Nicotinamide nucleotide transhydrogenase mRNA expression is related to human obesity. Obesity 21 529-534. (https://doi.org/10.1002/oby.20095)

Horscroft JA, Kotwica AO, Laner V, West JA, Hennis PJ, Levett DZH, Howard DJ, Fernandez BO, Burgess SL, Ament Z, et al. 2017 Metabolic basis to Sherpa altitude adaptation. PNAS 114 6382-6387. (https://doi. org/10.1073/pnas.1700527114)

Kahle M, Horsch M, Fridrich B, Seelig A, Schultheiß J, Leonhardt J, Irmler M, Beckers J, Rathkolb B, Wolf E, et al. 2013 Phenotypic comparison of common mouse strains developing high-fat dietinduced hepatosteatosis. Molecular Metabolism 2 435-446. (https://doi. org/10.1016/J.MOLMET.2013.07.009)

Kakimoto PA \& Kowaltowkski AJ 2016 Effects of high fat diets on rodent liver bioenergetics and oxidative imbalance. Redox Biology 8 216-225. (https://doi.org/10.1016/j.redox.2016.01.009)

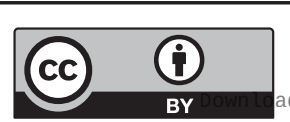

This work is licensed under a Creative Commons Attribution 4.0 International License. 
Khan NA, Auranen M, Paetau I, Pirinen E, Euro L, Forsström S, Pasila L, Velagapudi V, Carroll CJ, Auwerx J, et al. 2014 Effective treatment of mitochondrial myopathy by nicotinamide riboside, a vitamin B3. EMBO Molecular Medicine 6 721-731. (https://doi.org/10.1002/ emmm.201403943)

Kourtzidis IA, Stoupas AT, Gioris IS, Veskoukis AS, Margaritelis NV, Tsantarliotou M, Taitzoglou I, Vrabas IS, Paschalis V, Kyparos A, et al. 2016 The $\mathrm{NAD}(+)$ precursor nicotinamide riboside decreases exercise performance in rats. Journal of the International Society of Sports Nutrition 13 32. (https://doi.org/10.1186/s12970-016-0143-x)

Kourtzidis IA, Dolopikou CF, Tsiftsis AN, Margaritelis NV, Theodorou AA, Zervos IA, Tsantarliotou MP, Veskoukis AS, Vrabas IS, Paschalis V, et al. 2018 Nicotinamide riboside supplementation dysregulates redox and energy metabolism in rats: implications for exercise performance. Experimental Physiology 103 1357-1366. (https://doi.org/10.1113/EP086964)

Koza RA, Nikonova L, Hogan J, Rim JS, Mendoza T, Faulk C, Skaf J \& Kozak LP 2006 Changes in gene expression foreshadow diet-induced obesity in genetically identical mice. PLoS Genetics 2 e81. (https://doi. org/10.1371/journal.pgen.0020081)

Leduc-Gaudet JP, Reynaud O, Chabot F, Mercier J, Andrich DE, St-Pierre DH \& Gouspillou G 2018 The impact of a short-term high-fat diet on mitochondrial respiration, reactive oxygen species production, and dynamics in oxidative and glycolytic skeletal muscles of young rats. Physiological Reports 6 e13548. (https://doi.org/10.14814/phy2.13548)

Lee HJ, Hong YS, Jun W \& Yang SJ 2015 Nicotinamide riboside ameliorates hepatic metaflammation by modulating NLRP3 inflammasome in a rodent model of Type 2 diabetes. Journal of Medicinal Food 18 1207-1213. (https://doi.org/10.1089/jmf.2015.3439)

Lopert P \& Patel M 2014 Nicotinamide nucleotide transhydrogenase (Nnt) links the substrate requirement in brain mitochondria for hydrogen peroxide removal to the thioredoxin/peroxiredoxin $(\operatorname{Trx} / \operatorname{Prx})$ system. Journal of Biological Chemistry 289 15611-15620. (https://doi. org/10.1074/jbc.M113.533653)

Martens CR, Denman BA, Mazzo MR, Armstrong ML, Reisdorph N, McQueen MB, Chonchol M \& Seals DR 2018 Chronic nicotinamide riboside supplementation is well-tolerated and elevates NAD ${ }^{+}$in healthy middle-aged and older adults. Nature Communications 91286. (https://doi.org/10.1038/s41467-018-03421-7)

Mekada K, Abe K, Murakami A, Nakamura S, Nakata H, Moriwaki K, Obata Y \& Yoshiki A 2009 Genetic differences among C57BL/6 substrains. Experimental Animals 58 141-149. (https://doi.org/10.1538/ expanim.58.141)

Mills KF, Yoshida S, Stein LR, Grozio A, Kubota S, Sasaki Y, Redpath P, Migaud ME, Apte RS, Uchida K, et al. 2016 Long-term administration of nicotinamide mononucleotide mitigates age-associated physiological decline in mice. Cell Metabolism 24 795-806. (https://doi.org/10.1016/j. cmet.2016.09.013)

Mina AI, LeClair RA, LeClair KB, Cohen DE, Lantier L \& Banks AS 2018 CalR: a web-based analysis tool for indirect calorimetry experiments. Cell Metabolism 28 656.e1-666.e1. (https://doi.org/10.1016/j. cmet.2018.06.019)

Mukherjee S, Chellappa K, Moffitt A, Ndungu J, Dellinger RW, Davis JG, Agarwal B \& Baur JA 2017 Nicotinamide adenine dinucleotide biosynthesis promotes liver regeneration. Hepatology 65 616-630. (https://doi.org/10.1002/hep.28912)

Mukherjee S, Mo J, Paolella LM, Perry CE, Toth J, Hugo MM, Chu Q, Tong Q, Chellappa K \& Baur JA 2021 SIRT3 is required for liver regeneration but not for the beneficial effect of nicotinamide riboside. JCI Insight 6 e147193. (https://doi.org/10.1172/JCI. INSIGHT.147193)

Navarro CDC, Figueira TR, Francisco A, Dal'Bó GA, Ronchi JA, Rovani JC, Escanhoela CAF, Oliveira HCF, Castilho RF \& Vercesi AE 2017 Redox imbalance due to the loss of mitochondrial NAD(P)-transhydrogenase markedly aggravates high fat diet-induced fatty liver disease in mice. Free Radical Biology and Medicine 113 190-202. (https://doi. org/10.1016/j.freeradbiomed.2017.09.026)
Naznin F, Sakoda H, Okada T, Tsubouchi H, Waise TMZ, Arakawa K \& Nakazato M 2017 Canagliflozin, a sodium glucose cotransporter 2 inhibitor, attenuates obesity-induced inflammation in the nodose ganglion, hypothalamus, and skeletal muscle of mice. European Journal of Pharmacology 794 37-44. (https://doi.org/10.1016/j.ejphar.2016.11.028)

Nicholson A, Reifsnyder PC, Malcolm RD, Lucas CA, MacGregor GR, Zhang W \& Leiter EH 2010 Diet-induced obesity in two C57BL/6 substrains with intact or mutant nicotinamide nucleotide transhydrogenase (Nnt) gene. Obesity 18 1902-1905. (https://doi. org/10.1038/oby.2009.477)

Pesta D \& Gnaiger E 2012 High-resolution respirometry: OXPHOS protocols for human cells and permeabilized fibers from small biopsies of human muscle. Methods in Molecular Biology 25-58. (https://doi. org/10.1007/978-1-61779-382-0_3)

Pinho RA, Sepa-Kishi DM, Bikopoulos G, Wu MV, Uthayakumar A, Mohasses A, Hughes MC, Perry CGR \& Ceddia RB 2017 High-fat diet induces skeletal muscle oxidative stress in a fiber type-dependent manner in rats. Free Radical Biology and Medicine 110 381-389. (https:// doi.org/10.1016/j.freeradbiomed.2017.07.005)

Podrini C, Cambridge EL, Lelliott CJ, Carragher DM, Estabel J, Gerdin AK, Karp NA, Scudamore CL, Sanger Mouse Genetics Project, RamirezSolis R, et al. 2013 High-fat feeding rapidly induces obesity and lipid derangements in C57BL/6N mice. Mammalian Genome 24 240-251. (https://doi.org/10.1007/s00335-013-9456-0)

Purhonen J, Rajendran J, Tegelberg S, Smolander OP, Pirinen E, Kallijärvi J \& Fellman V $2018 \mathrm{NAD}^{+}$repletion produces no therapeutic effect in mice with respiratory chain complex III deficiency and chronic energy deprivation. FASEB Journal 32 fj201800090R. (https://doi.org/10.1096/ fj.201800090R)

Rendina-Ruedy E, Hembree KD, Sasaki A, Davis MR, Lightfoot SA, Clarke SL, Lucas EA \& Smith BJ 2015 A comparative study of the metabolic and skeletal response of C57BL/6J and C57BL/6N mice in a diet-induced model of Type 2 diabetes. Journal of Nutrition and Metabolism 2015 758080. (https://doi.org/10.1155/2015/758080)

Ronchi JA, Figueira TR, Ravagnani FG, Oliveira HC, Vercesi AE \& Castilho RF 2013 A spontaneous mutation in the nicotinamide nucleotide transhydrogenase gene of $\mathrm{C} 57 \mathrm{BL} / 6 \mathrm{~J}$ mice results in mitochondrial redox abnormalities. Free Radical Biology and Medicine 63 446-456. (https://doi.org/10.1016/j.freeradbiomed.2013.05.049)

Ronchi JA, Francisco A, Passos LAC, Figueira TR \& Castilho RF 2016 The contribution of nicotinamide nucleotide transhydrogenase to peroxide detoxification is dependent on the respiratory state and counterbalanced by other sources of NADPH in liver mitochondria. Journal of Biological Chemistry 291 20173-20187. (https://doi. org/10.1074/jbc.M116.730473)

Ryu D, Zhang H, Ropelle ER, Sorrentino V, Mázala DAG, Mouchiroud L, Marshall PL, Campbell MD, Ali AS, Knowels GM, et al. 2016 NAD $^{+}$ repletion improves muscle function in muscular dystrophy and counters global PARylation. Science Translational Medicine 8361 ra139. (https://doi.org/10.1126/scitranslmed.aaf5504)

Schöndorf DC, Ivanyuk D, Baden P, Sanchez-Martinez A, De Cicco S, Yu C, Giunta I, Schwarz LK, Di Napoli G, Panagiotakopoulou V, et al. 2018 The $\mathrm{NAD}^{+}$precursor nicotinamide riboside rescues mitochondrial defects and neuronal loss in iPSC and fly models of Parkinson's disease. Cell Reports 23 2976-2988. (https://doi.org/10.1016/j.celrep.2018.05.009)

Shi W, Hegeman MA, van Dartel DAM, Tang J, Suarez M, Swarts H, van der Hee B, Arola L \& Keijer J 2017 Effects of a wide range of dietary nicotinamide riboside (NR) concentrations on metabolic flexibility and white adipose tissue (WAT) of mice fed a mildly obesogenic diet. Molecular Nutrition and Food Research 61 1600878. (https://doi. org/10.1002/mnfr.201600878) (28211258)

Shi W, Hegeman MA, Doncheva A, Bekkenkamp-Grovenstein M, de Boer VCJ \& Keijer J 2019 High dose of dietary nicotinamide riboside induces glucose intolerance and white adipose tissue dysfunction in mice fed a mildly obesogenic diet. Nutrients 112439 . (https://doi. org/10.3390/nu11102439)

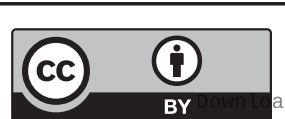

This work is licensed under a Creative Commons Attribution 4.0 International License. 
Smoczek M, Vital M, Wedekind D, Basic M, Zschemisch NH, Pieper DH, Siebert A, Bleich A \& Buettner M 2020 A combination of genetics and microbiota influences the severity of the obesity phenotype in dietinduced obesity. Scientific Reports 10 6118. (https://doi.org/10.1038/ s41598-020-63340-w)

Spaulding HR, Quindry T, Hammer K, Quindry JC \& Selsby JT 2019 Nutraceutical and pharmaceutical cocktails did not improve muscle function or reduce histological damage in D2-mdx mice. Journal of Applied Physiology 127 1058-1066. (https://doi.org/10.1152/ japplphysiol.00162.2019)

Stromsdorfer KL, Yamaguchi S, Yoon MJ, Moseley AC, Franczyk MP, Kelly SC, Qi N, Imai S-I \& Yoshino J 2016 NAMPT-mediated NAD(+) biosynthesis in adipocytes regulates adipose tissue function and multiorgan insulin sensitivity in mice. Cell Reports 16 1851-1860. (https:// doi.org/10.1016/j.celrep.2016.07.027)

Toye AA, Lippiat JD, Proks P, Shimomura K, Bentley L, Hugill A, Mijat V, Goldsworthy M, Moir L, Haynes A, et al. 2005 A genetic and physiological study of impaired glucose homeostasis control in C57BL/6J mice. Diabetologia 48 675-686. (https://doi.org/10.1007/ s00125-005-1680-z)

Trammell SAJ, Weidemann BJ, Chadda A, Yorek MSMA, Holmes A, Coppey LJ, Obrosov A, Kardon RH, Yorek MA \& Brenner C 2016 Nicotinamide riboside opposes type 2 diabetes and neuropathy in mice. Scientific Reports 6 26933. (https://doi.org/10.1038/srep26933)

Wang S, Wan T, Ye M, Qiu Y, Pei L, Jiang R, Pang N, Huang Y, Liang B, Ling W, et al. 2018 Nicotinamide riboside attenuates alcohol induced liver injuries via activation of SirT1/PGC-1 $1 \alpha /$ mitochondrial biosynthesis pathway. Redox Biology 17 89-98. (https://doi. org/10.1016/J.REDOX.2018.04.006)
Williams LM, Campbell FM, Drew JE, Koch C, Hoggard N, Rees WD, Kamolrat T, Thi Ngo H, Steffensen IL, Gray SR, et al. 2014 The development of diet-induced obesity and glucose intolerance in C57BL/6 mice on a high-fat diet consists of distinct phases. PLOS ONE 9 e106159. (https://doi.org/10.1371/journal.pone.0106159)

Wong N, Blair AR, Morahan G \& Andrikopoulos S 2010 The deletion variant of nicotinamide nucleotide transhydrogenase (Nnt) does not affect insulin secretion or glucose tolerance. Endocrinology 151 96-102. (https://doi.org/10.1210/en.2009-0887)

Yoon MJ, Yoshida M, Johnson S, Takikawa A, Usui I, Tobe K, Nakagawa T, Yoshino J \& Imai S 2015 SIRT1-mediated eNAMPT secretion from adipose tissue regulates hypothalamic NAD + and function in mice. Cell Metabolism 21 706-717. (https://doi.org/10.1016/j.cmet.2015.04.002)

Yoshino J, Mills KF, Yoon MJ \& Imai S 2011 Nicotinamide mononucleotide, a key $\mathrm{NAD}^{+}$intermediate, treats the pathophysiology of diet- and ageinduced diabetes in mice. Cell Metabolism 14 528-536. (https://doi. org/10.1016/j.cmet.2011.08.014)

Zhang H, Ryu D, Wu Y, Gariani K, Wang X, Luan P, DAmico D, Ropelle ER, Lutolf MP, Aebersold R, et al. $2016 \mathrm{NAD}^{+}$repletion improves mitochondrial and stem cell function and enhances life span in mice. Science 352 1436-1443. (https://doi.org/10.1126/science.aaf2693)

Zhou CC, Yang X, Hua X, Liu J, Fan MB, Li GQ, Song J, Xu TY, Li ZY, Guan YF, et al. 2016 Hepatic NAD(+) deficiency as a therapeutic target for NAFLD in aging. British Journal of Pharmacology 173 2352-2368. (https://doi.org/10.1111/bph.13513)

Zhou D, Pan Q, Shen F, Cao HX, Ding WJ, Chen YW \& Fan JG 2017 Tota fecal microbiota transplantation alleviates high-fat diet-induced steatohepatitis in mice via beneficial regulation of gut microbiota. Scientific Reports 7 1529. (https://doi.org/10.1038/s41598-017-01751-y)

Received in final form 14 July 2021

Accepted 9 August 2021

Accepted Manuscript published online 9 August 2021 (c) 2021 The authors Published by Bioscientifica Ltd. Printed in Great Britain
This work is licensed under a Creative Commons Attribution 4.0 International License.

ded from Bioscientifica.com at $04 / 26 / 2023 \quad 07: 44: 22 A M$ 